\title{
Desempenho térmico de envoltórias vegetadas em edificações no sudeste brasileiro
}

\author{
Thermal performance of green envelopes in buildings in \\ the Brazilian southeast
}

\section{Carla Matheus \\ Fernando Durso Neves Caetano \\ Denise Damas de Oliveira Morelli Lucila Chebel Labaki}

\section{Resumo}

$\Delta$

avaliação do desempenho térmico de edificações que utilizam coberturas verdes, paredes vivas ou paredes verdes como elemento de proteção da envoltória é um campo de grande importância para os profissionais de arquitetura e engenharia, por minimizar o ganho de calor, proporcionar melhor condição térmica e aprimorar seu desempenho. Este trabalho apresenta três diferentes estudos de desempenho térmico com revestimentos vegetais: 1) um estudo de caso com cobertura verde, 2) um estudo experimental com parede viva, e 3) um estudo de caso com parede verde, todos com medições comparativas e simultâneas entre superfícies expostas e protegidas pelo verde. Os parâmetros medidos foram temperatura, umidade relativa, velocidade do ar, temperatura radiante média e temperatura das superfícies internas e externas das envoltórias. Tais análises levaram à conclusão de que o uso da vegetação como elemento de proteção em coberturas e fachadas atua positivamente sobre os fluxos de calor na envoltória, representando uma importante ferramenta para o controle térmico passivo de altas temperaturas no interior das edificações.

Carla Matheus Universidade Estadual de Campinas Campinas - SP - Brasil

Fernando Durso Neves Caetano Universidade Estadual de Campinas Campinas - SP - Brasil

Denise Damas de Oliveira Morelli Universidade Estadual de Campinas Campinas - SP - Brasil

Lucila Chebel Labaki Universidade Estadual de Campinas Campinas - SP - Brasil

Recebido em 01/05/15 Aceito em 07/09/15
Palavras-chaves: Conforto térmico. Vegetação. Cobertura verde. Parede viva. Parede verde.

\section{Abstract}

The evaluation of the thermal performance of buildings using green roofs, living walls or green walls as envelope protection elements is a very important tool for architects and engineers to minimize heat gain, provide better thermal condition and improve thermal performance. This paper presents three different studies of thermal performance of buildings with green cover: 1) a case study of a green roof, 2) an experimental study of a living wall, and 3) a case study of a green wall; all of which include comparative and concurrent measurements between exposed surfaces and surfaces protected by vegetation. The parameters measured were air temperature, relative humidity, air speed and mean radiant temperature, as well as the inner and outer temperature of the walls. Those analyses led to the conclusion that the use of vegetation as a protection element on roofs and façades acts positively on the heat flows in the envelope, representing an important tool for passive thermal control of high temperatures inside the buildings.

Keywords: Thermal performance. Vegetation. Green roof. Living wall. Green wall. 


\section{Introdução}

A vegetação tem sido sistematicamente utilizada como estratégia de condicionamento ambiental passivo, integrando um conjunto de estratégias bioclimáticas utilizadas por profissionais da construção civil. Por outro lado, a grande demanda pelo uso do solo urbano induz ao surgimento de novas pesquisas que buscam diferentes formas de trazer a vegetação para as cidades (GIVONI, 1991; NOWAK, 2006; PERINI; MAGLIOCCO, 2012).

Esse é o caso das pesquisas com revestimentos vegetais que avaliam a eficácia proporcionada pela vegetação em paredes e coberturas dos edifícios. De modo geral, a vegetação urbana oferece um condicionamento passivo indireto aos edifícios, resfriando o ar nas redondezas, que então alcançam as construções. Assim, além da grande disponibilidade de coberturas e paredes ociosas nas cidades, essa é a grande vantagem que os revestimentos vegetais apresentam sobre a vegetação urbana ao produzir um efeito amenizador com atuação direta na envoltória e no ambiente interno (LIU; BASS, 2005; DUNNETT; KINGSBURY, 2008).

O livro "Thermal Delight in Architecture", escrito por Lisa Heschong, foi publicado em 1979 com a intenção de ser uma coleção de exemplos da arquitetura vernacular de várias partes do mundo e ser uma referência para os projetistas. Apesar de ter sido escrito há mais de três décadas, seu conceito permanece muito atual. De acordo com Heschong (1979, p. VII): "Este trabalho começou com a hipótese que a função termal de um edifício possa ser usada como um elemento efetivo de design [...]". Segundo Heschong (1979), a qualidade térmica de um local pode fazer com que ele adquira um valor especial para as pessoas, afinal lugares são facilmente ligados a sensações térmicas e muitas vezes esses locais podem ter essa ligação pelo fato de a pessoa ter vivido alguma situação térmica confortável ali.

A arquitetura vernacular tem, através dos séculos, utilizado materiais locais que se adaptam bem ao clima da região. Com acertos e erros, foram muitas vezes se impondo por oferecer grande conforto térmico de maneira passiva. Apesar de haver uma enorme variedade de soluções, de acordo com Coch (1998) é interessante observar como modelos de arquitetura praticamente idênticos podem ser observados em climas similares, mesmo sendo em regiões geográficas e culturas diferentes.

Ao redor do mundo a arquitetura vernacular apresenta uma adaptação térmica altamente sofisticada. Por exemplo, no deserto, onde a temperatura oscila muito entre o dia e a noite, o material ideal para a construção de paredes e coberturas é aquele que tenha alta capacidade térmica; esse é o caso da terra, material amplamente utilizado pela população do deserto. Por outro lado, povos de regiões quentes e úmidas constroem moradias que reduzem a massa térmica ao mínimo utilizando materiais como o bambu (HESCHONG, 1979).

Diferentes tipos de vegetação têm sido utilizados há séculos ao redor do mundo como forma de prover conforto térmico. No Brasil, Burle Marx projetou vários jardins em coberturas e fez uso extensivo de trepadeiras e epífitas em seu trabalho, criando uma cultura na qual o uso inovativo de plantas encontra uma audiência receptiva (DUNNETT; KINGSBURY, 2008).

Coberturas verdes têm sido utilizadas tanto em países frios como em quentes, para, entre outros benefícios, ajudar a manter a temperatura interna do ambiente mais agradável e constante. Isso porque a transferência de calor de uma cobertura vegetada é diferente de uma cobertura simples, pois fatores climáticos externos - radiação solar, temperatura externa, umidade relativa e vento são reduzidos ao passarem pela folhagem da cobertura

(EUMORFOPOULOU;

ARAVANTINOS, 1998). A eficácia da capacidade de isolamento térmico de uma cobertura relvada é facilmente comprovada nas casas de turfa da Islândia, que são habitadas, mesmo no inverno, sem aquecimento artificial (MINKE, 2010).

Por outro lado, atualmente as fachadas dos edifícios têm recebido um grande enfoque no processo de recuperação das áreas verdes urbanas, principalmente nos grandes centros, pois nestes locais a verticalização acentuada dos edifícios favorece a inserção de peles verdes de configuração vertical. Com isso, a pesquisa de novas tecnologias que aproveitem melhor a ampla disponibilidade de paredes tem florescido ao redor do mundo (KÖHLER, 2008).

Tradicionalmente, as peles verticais têm sido implantadas nas edificações através das plantas trepadeiras, numa tipologia conhecida como paredes verdes. Essa prática foi estabelecida há muito tempo em parte da Europa e é utilizada com espécies escaladoras que não necessitam de nenhum suporte auxiliar.

Dunnett e Kingsbury (2008) afirmam que o uso da parede verde (trepadeira) pode reduzir a temperatura do ambiente interno devido ao sombreamento proporcionado à superfície da edificação. Segundo os autores, no inverno o sistema também protege a parede dos ventos frios

72 Matheus, C.; Caetano, F. D. N.; Morelli, D. D. de O.; Labaki, L. C. 
por meio dos entrelaçados na ramificação da trepadeira, evitando a perda de calor do ambiente interno. Entretanto, Yeang (2000) ressalta que o aumento da resistência térmica proporcionado pela parede verde sempre vai depender do tipo de planta utilizada e de sua densidade foliar, pois uma folhagem mais aberta torna-se permeável à radiação solar e a influxos de ar, reduzindo assim o efeito de isolamento térmico que o ar estagnado entre a folhagem proporciona.

Nas configurações mais recentes, produzidas com maior incorporação tecnológica, observa-se um esquema técnico similar ao das coberturas verdes. Denominadas paredes vivas, tais configurações agregam o meio de crescimento diretamente à envoltória através de recipientes modulares. Por um lado, isso libera as plantas de sua dependência direta do solo, mas devido a sua configuração vertical e à pequena espessura do substrato, sua viabilização se torna mais complexa, fazendo-se necessário o uso de sistemas de apoio à nutrição e hidratação (DUNNETT; KINGSBURY, 2008; OTTELÉ et al., 2011).

Esses requisitos, embora aumentem o custo inicial das paredes vivas, trazem novas possibilidades, como maior poder de isolamento térmico através das diversas camadas do sistema; expansão vertical praticamente ilimitada; facilidade de instalação e substituição do sistema, com a obtenção de um efeito visual imediato; e possibilidade de uso de diversas espécies, trazendo um interesse ecológico e riqueza visual às fachadas.

Cheng, Cheung e Chu (2010), em seu estudo com paredes verdes em Hong Kong, concluíram que o atraso térmico no aumento da temperatura do ambiente com revestimento com vegetação poderia mitigar o impacto potencial do calor solar que continuaria a afetar o espaço interior depois do pôr do sol; com uma cobertura verde vigorosa em uma fachada, os moradores poderiam ser beneficiados por um ambiente mais frio e contas de eletricidade mais baratas, além dos méritos ecológicos dos painéis verticais verdes.

O objetivo deste trabalho é expor o comportamento térmico de fachadas e coberturas com revestimentos vegetais e avaliarsua capacidade de atenuar os ganhos indesejáveis de calor no ambiente interno. Espera-se, através dos resultados, indicar o potencial de integração da vegetação nos edifícios e de desenvolvimento de projetos que utilizem esse recurso como estratégia de condicionamento passivo.

\section{Método}

Para atingir os objetivos foi estabelecida uma análise detalhada dos diferentes objetos de estudo:

(a) um estudo de caso comparativo com cobertura verde;

(b) um estudo experimental comparativo com parede viva; e

(c) um estudo de caso comparativo com parede verde.

Cada uma dessas tipologias foi abordada dentro de pesquisas de mestrado desenvolvidas no Laboratório de Conforto Ambiental e Física Aplicada da Unicamp ${ }^{1}$, e os procedimentos e equipamentos de medição adotados foram os mesmos. Os dados ambientais coletados automaticamente em intervalos de $10 \mathrm{~min}$ foram:

(a) temperatura e umidade do ar; temperatura de globo negro;

(b) velocidade do ar; e

(c) temperaturas superficiais.

$\mathrm{O}$ experimento com a cobertura verde foi realizado na cidade de Atibaia, SP. Considerada uma estância climática, ela se localiza na latitude de $23^{\circ} 07^{\prime} 01^{\prime \prime} \mathrm{S}$ e longitude $46^{\circ} 33^{\prime} 01^{\prime}$ 'O, e possui altitude de $803 \mathrm{~m}$. Já os estudos com a parede verde e a parede viva foram realizados na cidade de Campinas, SP. Com uma área de aproximadamente $800 \mathrm{~km}^{2}$, ela é caracterizada pela alta taxa de urbanização e industrialização. Sua latitude é de 22053'20''S, elongitude de $47^{\circ} 10^{\prime} 15^{\prime}$ 'O, e possui altitude de $694 \mathrm{~m}$.

\section{Cobertura verde}

O objeto de estudo da cobertura verde foi uma residência na cidade de Atibaia; grande parte de sua área é semiaberta, interligada com o jardim. A residência está dividida em varanda, hall, banheiro e mezanino. A parede de divisa do terreno é feita de bloco de concreto e rebocada. As demais paredes são de tijolo modular de solo-cimento, com exceção das duas paredes internas do mezanino, que são de madeira (Figura 1).

A cobertura consiste de uma água de cobertura verde extensiva e de uma água de cobertura cerâmica. Há um vão entre as duas águas da cobertura, o qual permite a passagem de ar (Figura

\footnotetext{
${ }^{1}$ MATHEUS, C. Conforto Térmico em Uma Residência em Forma de Varanda Com Cobertura Verde. Campinas: Unicamp, 2013.

CAETANO, F. D. N. Influência de Muros Vivos Sobre o Desempenho Térmico de Edifícios. Campinas: Unicamp, 2014. MORELLI, D. D. O. Paredes Verdes: vegetação como qualidade ambiental no espaço construído. Campinas: Unicamp, 2009.
} 
1). A estrutura da cobertura é feita em tesouras de madeira serrada e está apoiada em pilares de madeira roliça e na parede de divisa. A geomembrana utilizada para impermeabilização se apresentou extremamente eficiente, bloqueando totalmente a passagem de umidade do substrato para o OSB. A cobertura, com a geomembrana, foi instalada em 2006 e se mantém em excelente estado. A manutenção é esporádica, uma vez que a camada de substrato é fina e com isso a grama não cresce em demasia. É feita apenas para a retirada de eventuais ervas daninhas, que nascem de sementes trazidas pelo vento ou por pássaros.

\section{Medições}

O critério para escolha dos pontos se baseou em áreas mais utilizadas e também naquelas que perceptivelmente apresentam maiores diferenças de ventilaçãoe temperatura. Foram definidos seis pontos (Figura 2). Todos os pontos foram nomeados com letra maiúscula para diferenciar dos nomes dos ambientes ou dos nomes de coberturas: Cobertura Verde1 (CV1), próximo ao hall; Cobertura Verde2 (CV2), próximo da área externa; Cobertura Cerâmica1 (CC1), próximo das paredes; Cobertura Cerâmica2 (CC2), próximo da área externa; Hall (HA), ponto central no hall; e Ponto Externo (EX), utilizado como comparação com os pontos estudados (Figura 2).

Foram instalados dois registradores de temperatura superficial, um na área interna da cobertura verde, fixado em um OSB, e o outro na área interna da cobertura cerâmica, fixado em uma telha cerâmica (Figura 3). Os registradores foram posicionados de maneira equivalente nas duas coberturas, ou seja, recebendo a mesma quantidade de radiação solar durante o dia.

Figura 1 - (a) Perspectiva e (b) corte da edificação com a cobertura verde
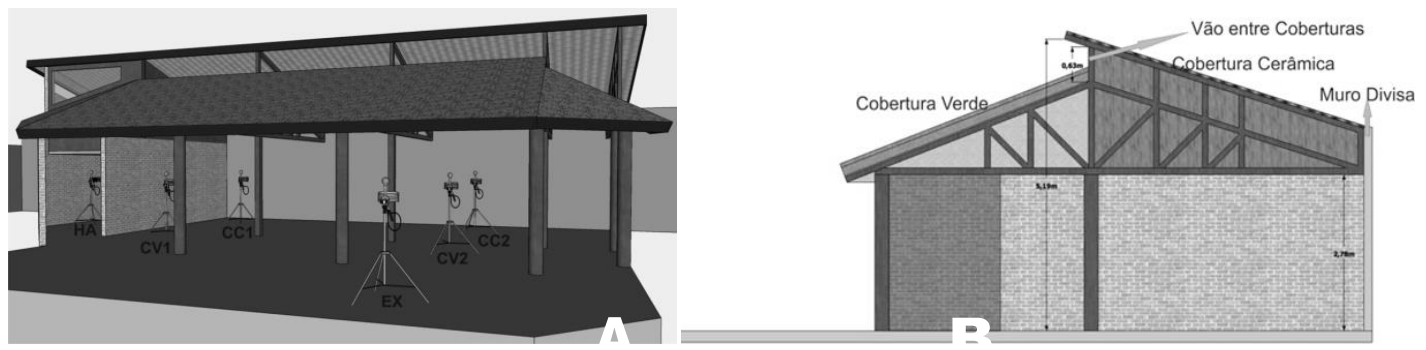

Figura 2 - Planta da edificação com os pontos de medição

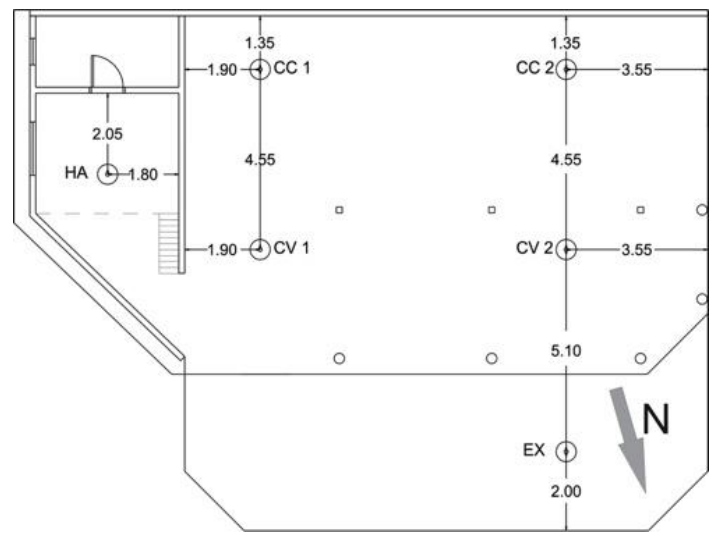

Figura 3 - Sensores de temperatura superficial fixados sob a (a) cobertura verde e uma (b) telha cerâmica
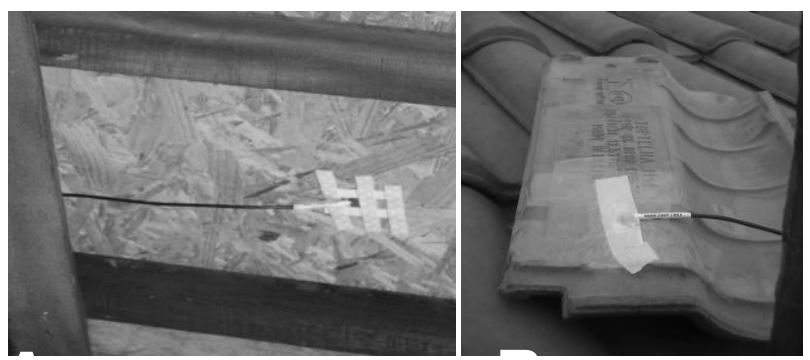

74 Matheus, C.; Caetano, F. D. N.; Morelli, D. D. de O.; Labaki, L. C. 


\section{Parede viva}

$\mathrm{O}$ experimento com o sistema de parede viva investigou a influência de uma de suas tipologias sobre o comportamento térmico da envoltória e do interior da edificação. Para seu desenvolvimento foi escolhida uma torre de três pavimentos, sendo o pavimento superior utilizado como reservatório de água, e os dois inferiores para depósito de material. Essa configuração favoreceu o experimento porque aumentou muito a inércia da cobertura, ocasionando maior influência da alvenaria do $1^{\circ}$ e $2^{\circ}$ pavimentos no ambiente térmico interno. Em relação aos materiais, a alvenaria era composta de blocos de concreto com reboco interno e externo pintados com tinta acrílica na cor cinza-escuro.

A parede viva foi instalada nas fachadas norte e oeste do primeiro pavimento da torre, enquanto o segundo pavimento foi utilizado para a comparação das medições (Figura 4). Os módulos de parede viva foram pré-cultivados com 12 espécies selecionadas segundo critérios de sobrevivência, funcionalidade e aspecto visual, e formaram uma composição mista cujo efeito de amenização térmica foi analisado em conjunto. Para a sobrevivência das plantas foi utilizado um sistema de fertirrigação por gotejamento, associado a um substrato altamente poroso e absorvente.

De acordo com Dunnet e Kingsbury (2008), uma das maiores dificuldades para a consolidação de sistemas de muros vivos reside na hidratação das plantas. Devido a sua configuração vertical, grande exposição ambiental e fixação das raízes nas placas (diferente das trepadeiras, com fixação no solo), a água do sistema escoa e evapora muito rápido, colocando todo o empreendimento em risco. Para superar isso geralmente é necessário o uso da fertirrigação. Neste experimento tanto o sistema de nutrição quanto o de hidratação foram pensados dessa forma, com ativação da bomba hidráulica espaçada em intervalos ao longo do dia, de modo a fornecer diariamente $150 \mathrm{ml}$ de solução nutritiva por bolsa e distribuí-la uniformemente, evitando o escoamento.

A formulação do substrato também foi outro ponto sensível do projeto, já que uma boa retenção de água e a aeração das raízes (representada pelo equilíbrio entre macro e microporosidade) são requisitos de sobrevivência das plantas. Para isso se utilizou uma mistura entre porções granulares e fibrosas do mesocarpo do coco (fibra de coco, $85 \%$ ) com o mineral perlita $(15 \%)$, obtendo-se porosidade de $87 \%$, retenção média de líquidos de $400 \mathrm{ml}$ por litro de substrato e densidade aparente baixíssima $\left(71 \mathrm{~kg} / \mathrm{m}^{3}\right)$. Além de beneficiar a saúde das plantas, tal substrato também impõe baixo carregamento estrutural à alvenaria (IRWIN, 2013).

\section{Medições}

Após a instalação das placas, o comportamento da alvenaria começou a ser monitorado simultaneamente em sua porção exposta $\left(2^{\circ}\right.$ pavimento) e protegida pela pele vegetal. A coleta das temperaturas superficiais se deu através de termopares instalados nas superfícies interna e externa das paredes, e no caso da parede viva termopares adicionais à frente das placas, entre a folhagem. Já no ambiente interno foi implantado um conjunto de equipamentos para a medição da temperatura e umidade do ar, e temperatura de globo negro, montados num tripé para cada pavimento (Figura 5). O experimento ocorreu em meses de verão (dez/2013 a jan/2014), e a análise estatística dos dados excluiu dias chuvosos, nublados, e com temperaturas inferiores às médias históricas para o período.

Figura 4 - Torre com a parede viva experimental: fachadas norte (maior) e oeste (menor)
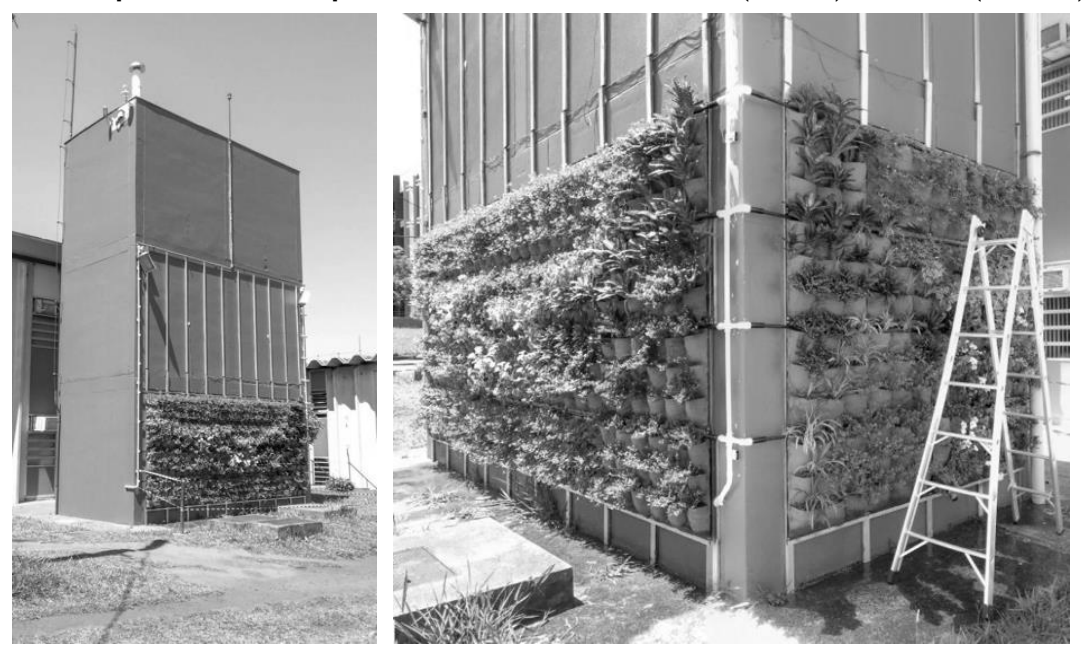
Figura 5 - Esquema de montagem e medições da parede viva
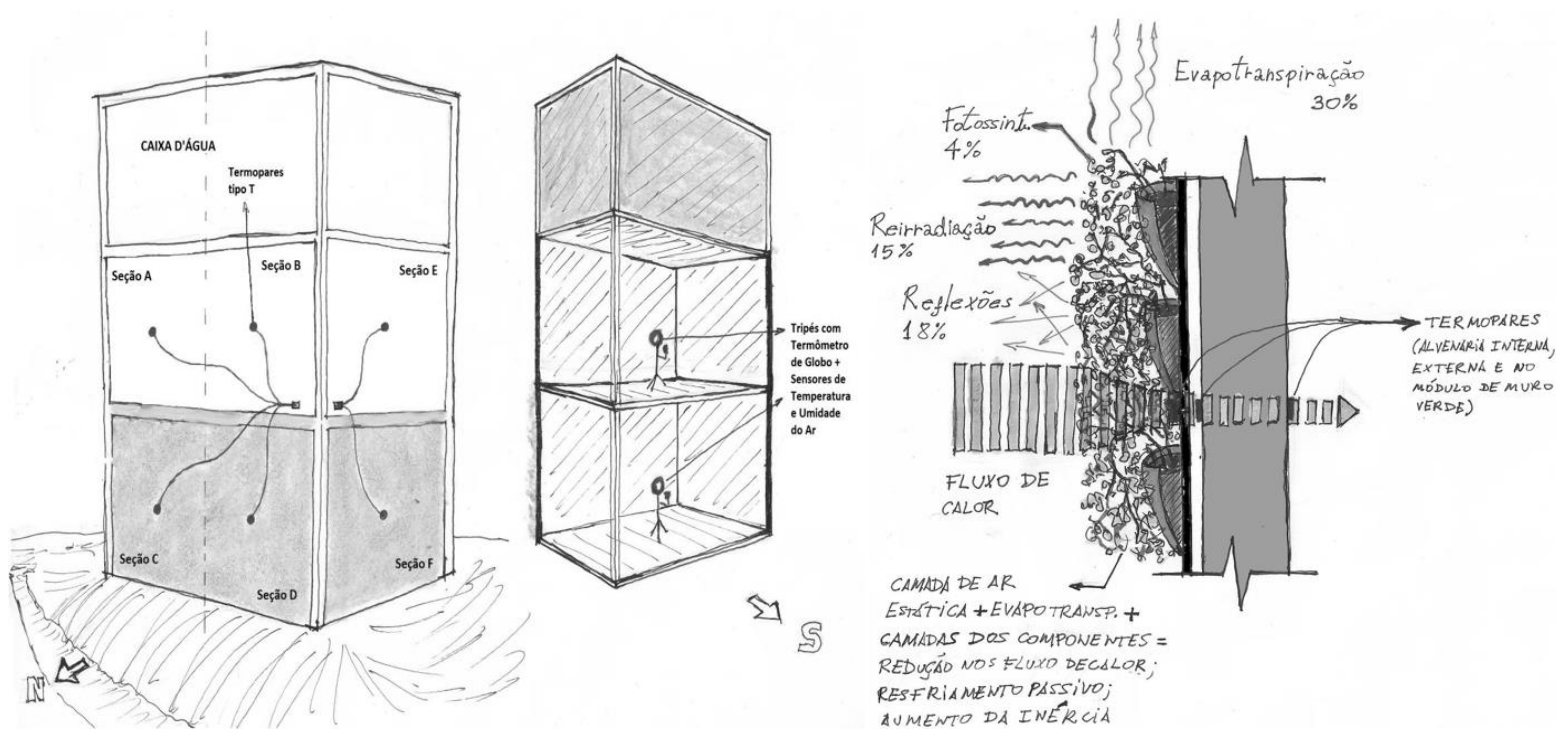

\section{Parede verde}

A análise comparativa da influência da trepadeira no comportamento térmico de edificações foi realizada nos períodos do verão e do inverno. Os dados obtidos foram medidos em ambientes edificados como construções idênticas. O único parâmetro diferenciador foi uma fachada com trepadeira e outra sem trepadeira.

A primeira edificação analisada é de uso residencial, utilizada por estudantes, conhecida na cidade como moradia estudantil. Os dois apartamentos possuem área total de $21,00 \mathrm{~m}^{2}$ cada, com paredes construídas de bloco cerâmico e reboco, totalizando $19 \mathrm{~cm}$ de espessura, com pintura interna na cor branca, e externa em amarelo. Possuem piso cerâmico de cor clara. A edificação possui dois blocos de apartamentos, ambos com dois pavimentos. O primeiro bloco não possui trepadeira na fachada, e o segundo bloco possui trepadeira (Figura 6).

A trepadeira utilizada, Parthenocissus tricuspidata (hera-japonesa),possui caule muito ramificado, semilenhoso, com ramos muito longos, delgados e flexíveis, que se elevam apoiando-se em muros, fachadas ou árvores por meio de raízes adventícias ou grampiformes. Essas são raízes aéreas com forma de grampos, que têm por função a fixação dos vegetais em suportes ou paredes, com folhas de tamanhos variáveis de cor verde e brilhante. No inverno, as folhas caem, mas antes, em casos de climas temperados, as bordas passam pelas cores avermelhadas e roxas (LORENZI; SOUZA, 2008).

\section{Medições}

Para a instalação dos equipamentos, devido à dimensão dos apartamentos, o conjunto para medições no interior foi instalado debaixo da janela, na fachada frontal, voltada para sudeste. As medições, realizadas no período de verão e inverno de 2009, ocorreram simultaneamente nos dois apartamentos. Os equipamentos fizeram os registros com intervalos de $10 \mathrm{~min}$, e os dados coletados foram temperatura e umidade do ar, temperatura do globo, velocidade do ar, e temperatura superficial das paredes interna e externa (Figura 7).

\section{Resultados e discussão}

Durante a realização das pesquisas, o resultado mais evidente que os dados ambientais coletados demonstraram foi o que parece ser uma concessão de capacidade autorreguladora à envoltória do edifício; tal comportamento é similar ao das fachadas ditas inteligentes, que se regulam através de mecanismos eletrônicos, entretanto acontecendo através de processo passivo, com o uso das peles vegetais.

Na cobertura verde, por exemplo, observou-se um atraso térmico de $2 \mathrm{~h}$, comparada à cobertura cerâmica no período do verão, e uma redução de até $9{ }^{\circ} \mathrm{C}$ em sua temperatura superficial interna; a cobertura verde atingiu sua hora mais quente às $15 \mathrm{~h} 00 \mathrm{~min}$, a uma temperatura de $32,64^{\circ} \mathrm{C}$; enquanto isso, a cobertura cerâmica atingiu o horário mais quente às 13h00min, a uma temperatura de $41,18^{\circ} \mathrm{C}$ (Figura 8 ). Nos horários mais frios a diferença máxima é de $2,65^{\circ} \mathrm{C}$, às 06h00min, quando a temperatura da cobertura cerâmica é de $17,83^{\circ} \mathrm{C}$, e a da cobertura verde é de $20,48^{\circ} \mathrm{C}$.

O monitoramento da alvenaria com o sistema de parede viva apresentou dois resultados principais;

76 Matheus, C.; Caetano, F. D. N.; Morelli, D. D. de O.; Labaki, L. C. 
em primeiro lugar observou-se um aumento significativo na inércia térmica da envoltória. $\mathrm{Na}$ Figura 9, que apresenta medições de temperatura superficial externa na fachada oeste em um intervalo de 7 dias (3 a 10 de janeiro de 2014), é possível observar que o amortecimento térmico se deu por diferenças de temperatura de até $33^{\circ} \mathrm{C}$ durante o dia, e $3{ }^{\circ} \mathrm{C}$ à noite; já o atraso térmico alcançou valores de até $2 \mathrm{~h}$.

O comportamento térmico da envoltória indica que a pele vegetal não amorteceu arbitrariamente a temperatura superficial, mas tendeu a estabilizá-la dentro de determinado intervalo de temperatura (23-27 $\left.{ }^{\circ} \mathrm{C}\right)$, o qual é considerado adequado para o conforto térmico humano segundo a ASHRAE 55 (AMERICAN..., 2004). No interior do edifício observou-se um comportamento estabilizador similar, com a manutenção da temperatura do ar num intervalo de 24 a $28^{\circ} \mathrm{C}$; já no pavimento com a alvenaria exposta essa variação foi de 24,5 a $31^{\circ} \mathrm{C}$, um acréscimo de $3{ }^{\circ} \mathrm{C}$ no pico de temperatura.

Figura 6 - Edifícios de estudo e fachada com e sem trepadeira
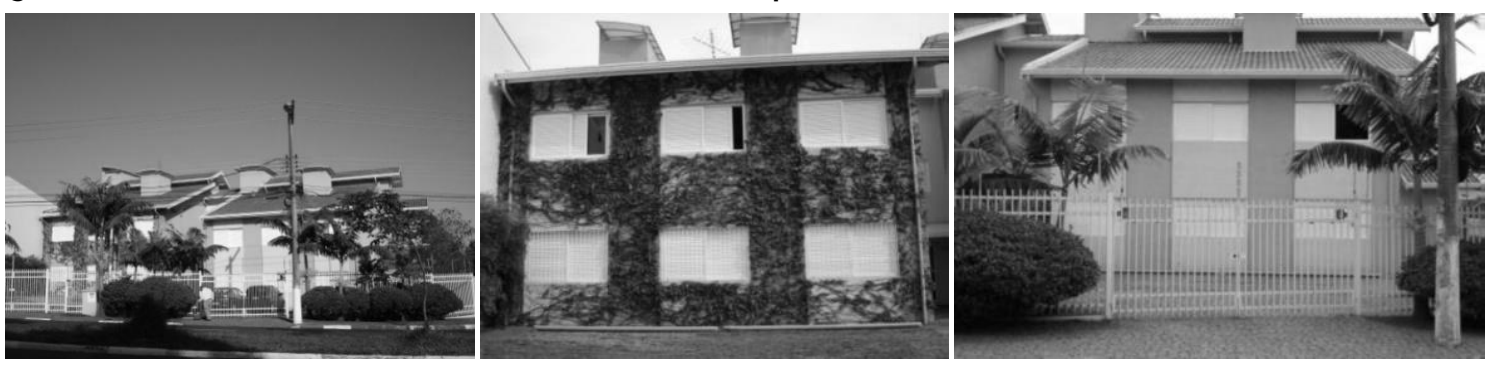

Figura 7 - Apartamentos de estudo com e sem trepadeira na fachada

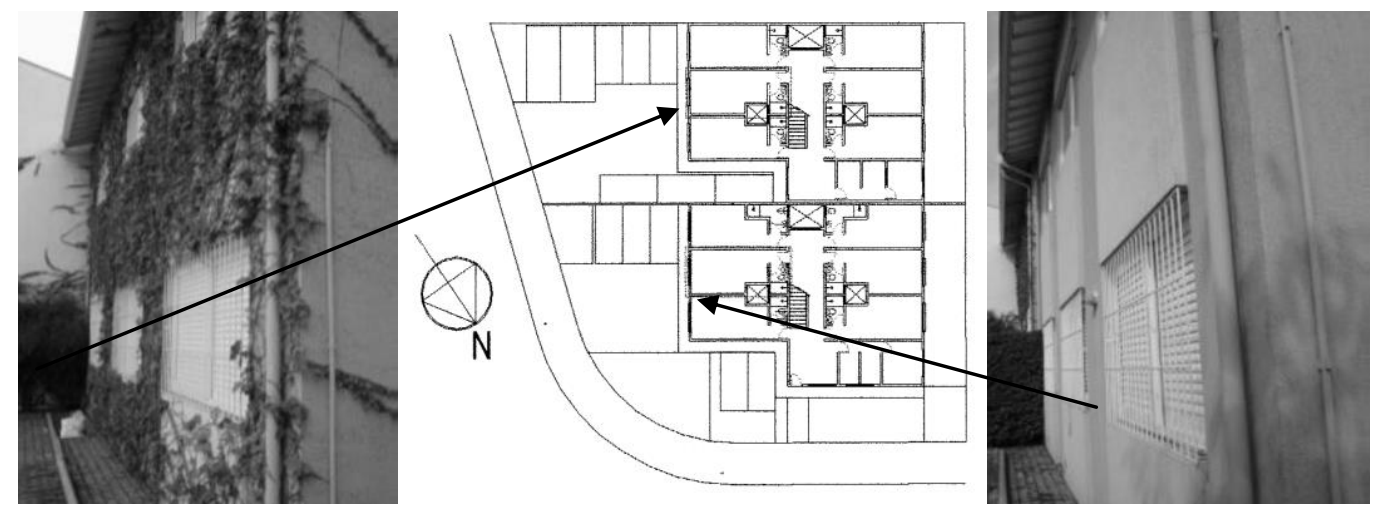

Figura 8 - Gráfico de temperaturas superficiaismédias internas da cobertura verde e cobertura de telha cerâmica

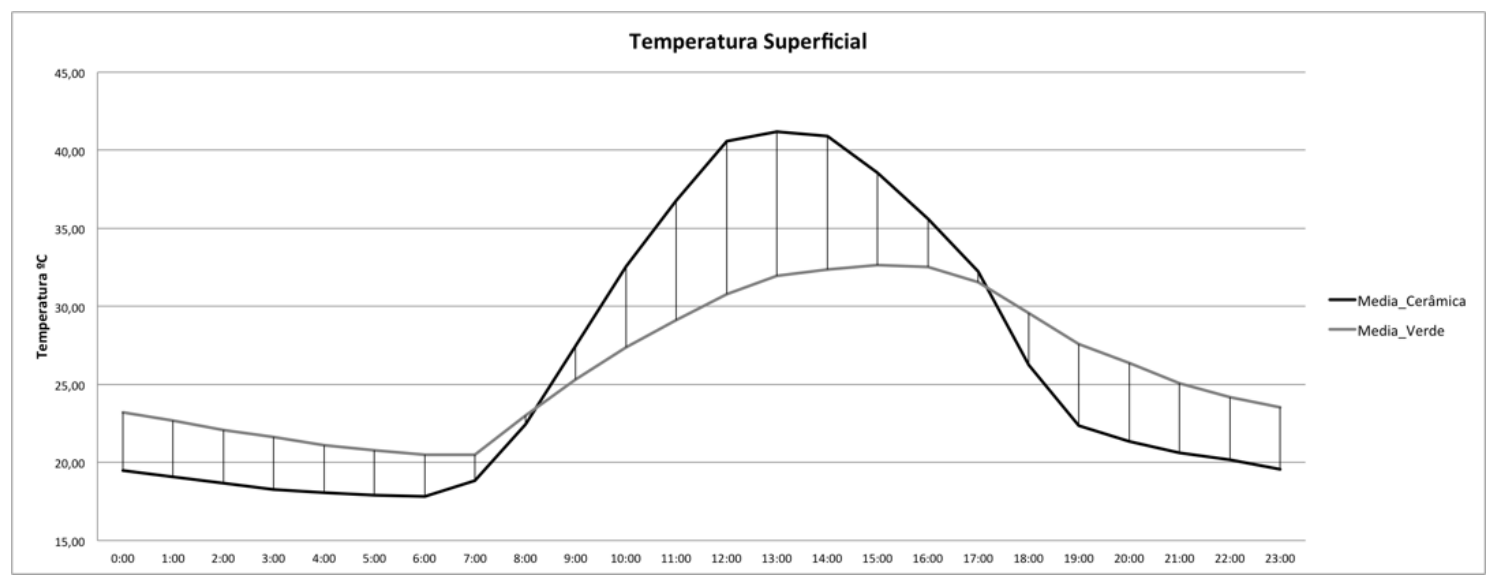


Figura 9 - Variação das temperaturas superficiais externas na parede nua e na parede viva

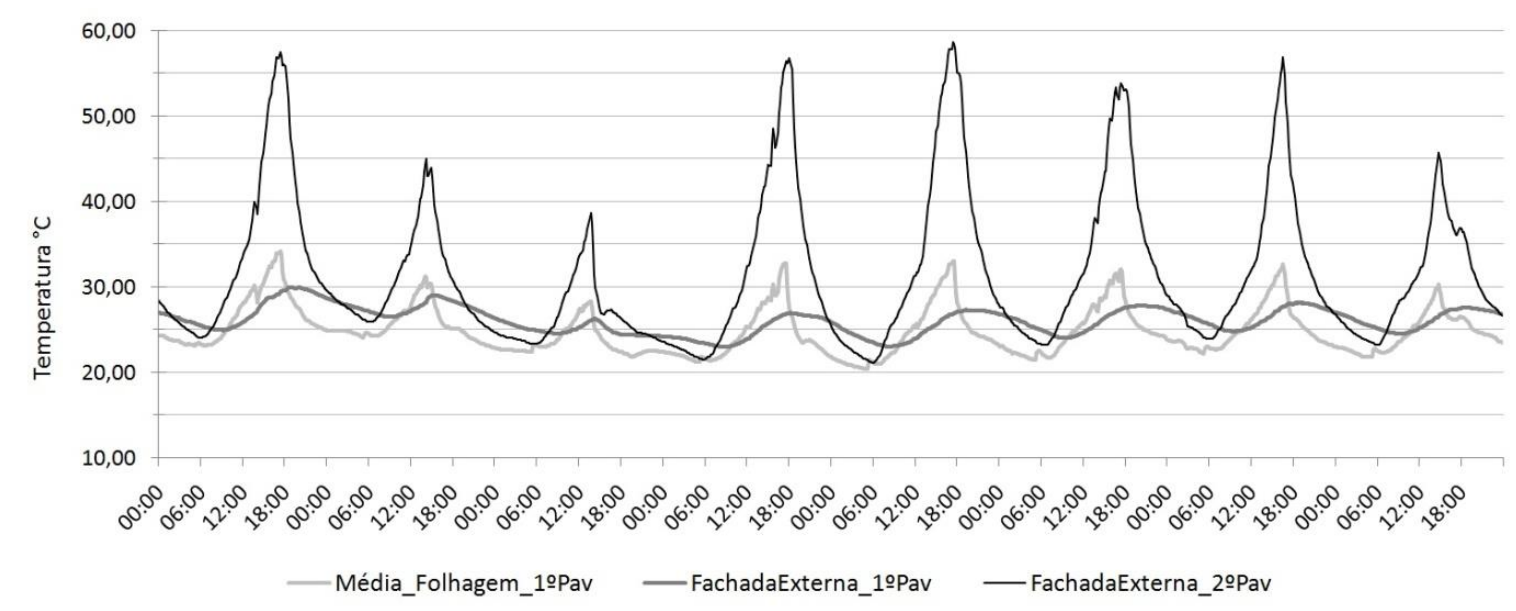

Já os dados obtidos na pesquisa com a parede verde demonstraram que o apartamento com a trepadeira manteve a temperatura do ar abaixo de $25^{\circ} \mathrm{C}$, enquanto o apartamento sem a trepadeira atingiu temperaturas de até $27^{\circ} \mathrm{C}$, principalmente no período da tarde. Essa diferença indica que a presença das trepadeiras foi capaz de minimizar os ganhos de calor no ambiente interno. Isso pode ser observado pela medição de temperaturas superficiais da parede com a trepadeira; neste localfoi obtido o valor médio de $27,9{ }^{\circ} \mathrm{C}$ para a superfície interna, e de $29,4{ }^{\circ} \mathrm{C}$ na superfície externa; já na parede exposta verificou-se que o apartamento que não possuía a trepadeira apresentou temperatura superficial interna média de $28,4{ }^{\circ} \mathrm{C}$, e uma temperatura superficial externa média de $30,5^{\circ} \mathrm{C}$.

No período do inverno a temperatura da área externa apresentou uma variação de $15^{\circ} \mathrm{C}$ a $32^{\circ} \mathrm{C}$, ao passo que no apartamento sem trepadeira a temperatura do ar obteve a variação de $18^{\circ} \mathrm{C}$ a 27 ${ }^{\circ} \mathrm{C}$, e o apartamento com trepadeira teve variação de $18^{\circ} \mathrm{C}$ a $25^{\circ} \mathrm{C}$. Aqui fica claro que a trepadeira mantém as temperaturas mais baixas durante o dia, e no período noturno reduz a emissão de radiação infravermelha devido à presença da folhagem (Figuras 10 e 11).

Os resultados obtidos demonstram que as folhagens das trepadeiras funcionam como um material isolante, ajudando a manter a temperatura mais baixa no ambiente interno do que no ambiente externo; e no período noturno, quando a parede devolve a radiação recebida para a área externa, isso ocorre lentamente, ficando o ambiente interno com uma temperatura amena, agradável para o usuário.

Na Tabela 1 é possível observar a síntese de todos esses resultados. Os valores de temperaturas do ar e temperatura superficial são fornecidos através das médias observadas durante as medições de cada sistema, associada à amplitude térmica entre a média das máximas e a média das mínimas. Assim, é interessante constatar que, mesmo em alguns casos que obtiveram médias iguais, a amplitude térmica foi tão alta que os valores extremos de temperatura nos ambientes sem as peles vegetais certamente proporcionaram desconforto térmico aos usuários sem o uso de condicionamento ativo.

\section{Conclusões}

A cobertura verde cumpriu uma de suas principais metas, que é a de proporcionar conforto térmico de maneira passiva para a edificação. O estudo de caso mostrou que a cobertura verde comparada com a telha cerâmica provoca atraso térmico, o qual tem como consequência uma temperatura mais estável para o ambiente construído. Verificase, pelos dados de temperatura superficial da cobertura verde, em relação à cobertura de telha cerâmica, um amortecimento térmico médio de $9^{\circ} \mathrm{C}$ nos horários mais quentes do dia, e um atraso médio de $2 \mathrm{~h}$.

Já a parede viva demonstrou uma grande capacidade de amenização térmica no período de verão, principalmente sobre as temperaturas superficiais de parede, proporcionando um amortecimento térmico médio de até $19^{\circ} \mathrm{C}$ e um atraso médio de até $4 \mathrm{~h}$ nos horários mais quentes do dia. Outro fator importante do uso desse sistema, parede viva, é que ele atuou como elemento estabilizador da temperatura superficial da edificação e da temperatura interna, proporcionando conforto térmico paraos usuários. 
Figura 10 - Período de verão - temperatura do ar externo e temperatura superficial de parede interna e externa dos apartamentos estudados

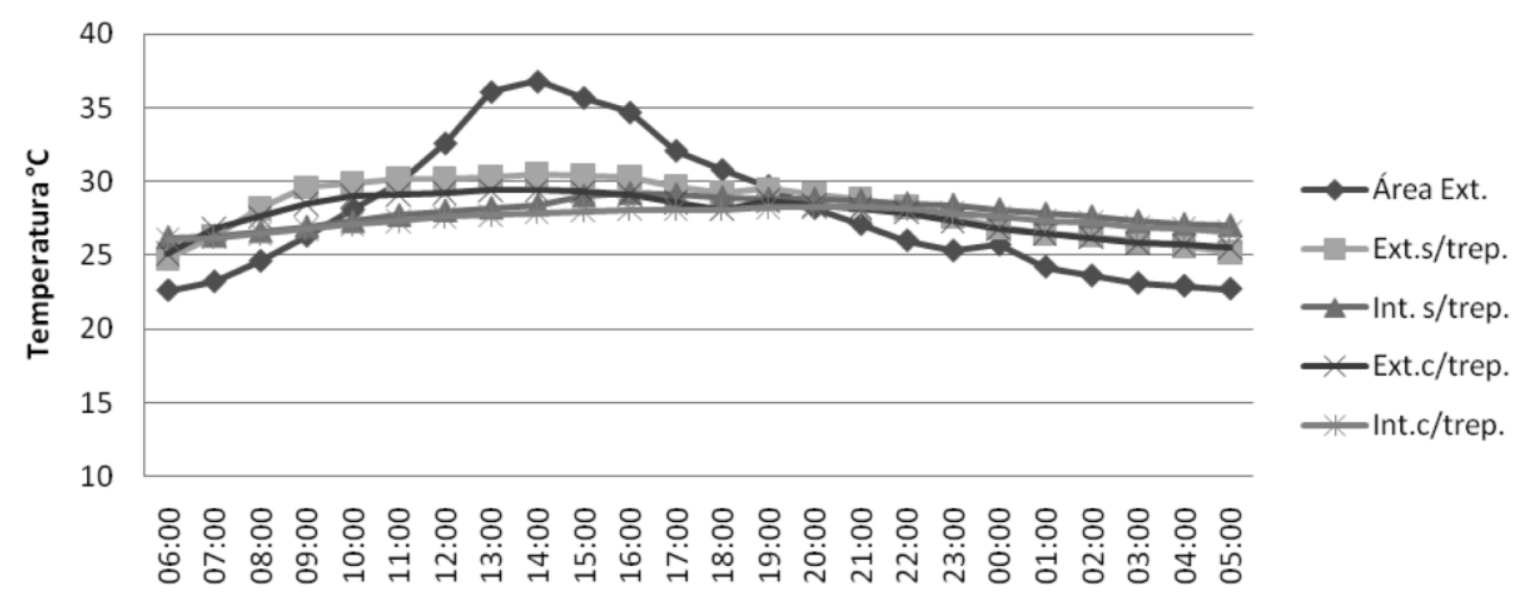

Figura 11 - Período de inverno - temperatura do ar externo e temperatura superficial de parede interna e externa dos apartamentos estudados

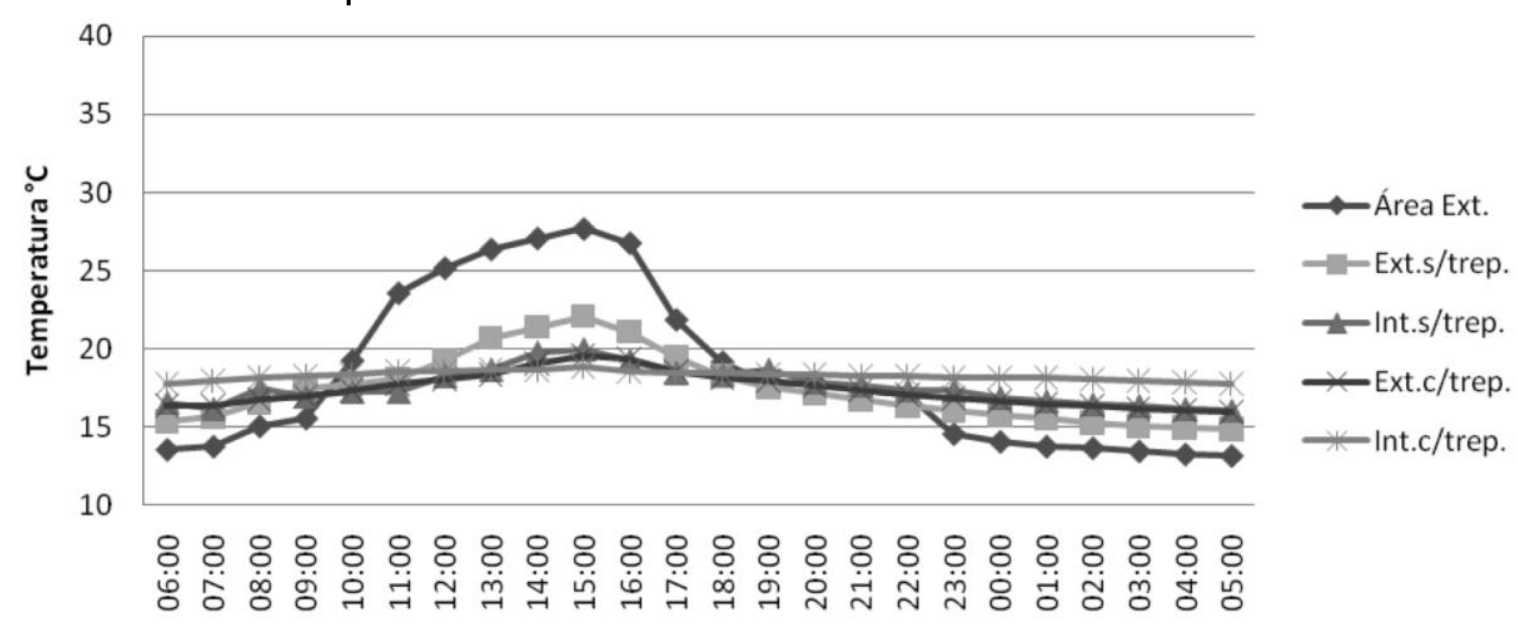

Tabela 1 - Síntese dos resultados de amenização térmica das peles vegetais

\begin{tabular}{|c|c|c|c|c|c|}
\hline \multicolumn{2}{|c|}{$\begin{array}{c}\text { MEDIÇÕES DE } \\
\text { VERÃO }\end{array}$} & $\begin{array}{c}\text { TAr Externo: } \\
\text { Média e } \\
\text { Amplitude } \\
\end{array}$ & $\begin{array}{c}\text { TAr Interno: } \\
\text { Média e } \\
\text { Amplitude } \\
\end{array}$ & TO: Tempe & $\begin{array}{l}\text { TSI: Média e } \\
\text { Amplitude }\end{array}$ \\
\hline \multirow{2}{*}{ 串 } & $\begin{array}{l}\text { Cobertura } \\
\text { Verde }\end{array}$ & $23,8^{\circ} \mathrm{C}\left(12,5^{\circ} \mathrm{C}\right)$ & $23,69^{\circ} \mathrm{C}\left(8,91^{\circ} \mathrm{C}\right)$ & $23,7^{\circ} \mathrm{C}\left(15,8^{\circ} \mathrm{C}\right)$ & $26,1^{\circ} \mathrm{C}\left(12,1^{\circ} \mathrm{C}\right)$ \\
\hline & $\begin{array}{l}\text { Cobertura - } \\
\text { Telha }\end{array}$ & $23,8^{\circ} \mathrm{C}\left(12,5^{\circ} \mathrm{C}\right)$ & $23,69^{\circ} \mathrm{C}\left(8,91^{\circ} \mathrm{C}\right)$ & $23,7^{\circ} \mathrm{C}\left(17,6^{\circ} \mathrm{C}\right)$ & $26,1^{\circ} \mathrm{C}\left(23,3^{\circ} \mathrm{C}\right)$ \\
\hline \multirow{2}{*}{ 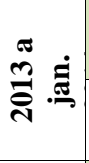 } & $\begin{array}{l}\text { Parede Viva } \\
\text { (Oeste) }\end{array}$ & $26,5^{\circ} \mathrm{C}\left(5,7^{\circ} \mathrm{C}\right)$ & $26,7^{\circ} \mathrm{C}\left(4,8^{\circ} \mathrm{C}\right)$ & $27,5^{\circ} \mathrm{C}\left(4^{\circ} \mathrm{C}\right)$ & $25,7^{\circ} \mathrm{C}\left(3,8^{\circ} \mathrm{C}\right)$ \\
\hline & $\begin{array}{l}\text { Parede Nua } \\
\text { (Oeste) }\end{array}$ & $26,5^{\circ} \mathrm{C}\left(5,7^{\circ} \mathrm{C}\right)$ & $28,0^{\circ} \mathrm{C}\left(7,5^{\circ} \mathrm{C}\right)$ & $28,7^{\circ} \mathrm{C}\left(7^{\circ} \mathrm{C}\right)$ & $29,4^{\circ} \mathrm{C}\left(15,0^{\circ} \mathrm{C}\right)$ \\
\hline \multirow{2}{*}{ 产 } & $\begin{array}{l}\text { Parede } \\
\text { Verde } \\
\end{array}$ & $36,8\left(14,2^{\circ} \mathrm{C}\right)$ & $26,7\left(2,5^{\circ} \mathrm{C}\right)$ & $27,2^{\circ} \mathrm{C}\left(0,5^{\circ} \mathrm{C}\right)$ & $27,9\left(1,8^{\circ} \mathrm{C}\right)$ \\
\hline & Parede Nua & $36,8\left(14,2^{\circ} \mathrm{C}\right)$ & $28,0\left(2,0^{\circ} \mathrm{C}\right)$ & $28,0^{\circ} \mathrm{C}\left(2,0^{\circ} \mathrm{C}\right)$ & $28,4\left(2,2^{\circ} \mathrm{C}\right)$ \\
\hline
\end{tabular}

Nota: Legenda:

TAr: temperatura do ar;

TSE: temperatura superficial externa; e

TSI: temperatura superficial interna. 
Em sentido similar, os resultados obtidos no estudo com a parede verde demonstram uma amenização da temperatura internados apartamentos devido à presença da trepadeira na fachada. As temperaturas superficiais da parede com a vegetação indicaram atraso térmico médio de até 2 h nos horários mais quentes do dia.

Conclui-se, portanto, que a presença do verde na envoltória dos edifícios, materializado através do uso de revestimentos vegetais, possui a capacidade de amenizar em diferentes escalas (dependendo da tipologia utilizada) os extremos de temperatura observados em regiões de clima tropical e subtropical, deslocando os picos de temperatura superficial interna para horários mais amenos do dia.

Os resultados aqui apresentados indicam a possibilidade de desenvolver projetos que adotem a vegetação nos edifícios como estratégia bioclimática, proporcionando maior equilíbrio microclimático, eficiência energética e conforto térmico no interior das edificações.

\section{Referências}

\section{AMERICAN SOCIETY OF HEATING, REFRIGERATING AND AIR CONDITIONING ENGINEERS. Standard 55: thermal environmental conditions for human occupancy. Atlanta, 2004.}

CHENG, C. Y.; CHEUNG, K. K. S.; CHU, L. M. Thermal Performance of a Vegetated Cladding System on Facade Walls. Building and Environment, v. 45, n. 8, p. 1779-1787, ago. 2010.

$\mathrm{COCH}, \mathrm{H}$. Bioclimatism in Vernacular Architecture. Renewable and Sustainable Energy Reviews, v. 2, n. 1/2, p. 67-87, 1998.

DUNNETT, N.; KINGSBURY, N. Planting Green Roofs and Living Walls. Portland, OR: Timber Press, 2008.
EUMORFOPOULOU, E.; ARAVANTINOS, D. The Contribution of a Planted Roof to the Thermal Protection of Buildings in Greece. Energy and Buildings, v. 27, n. 1, p. 29-36, 1998.

GIVONI, B. Impact of Planted Areas on Urban Environmental Quality: a review. Atmospheric Environment. Part B. Urban Atmosphere, v. 25, n. 3, p. 289-299, 1991.

\section{HESCHONG, L. Thermal Delight in}

Architecture. Cambridge: MIT Press, 1979.

IRWIN, G. Hydroponic Living Walls: irrigation. The Green Walls Column, 2013. Disponível em: <http://www.greenroofs.com/archives/green_walls .htm>. Acesso em: 25 mar. 2014.

KÖHLER, M. Green Facades: a view back and some visions. Urban Ecosystems, v. 11, n. 4, p. 423-436, 28 maio 2008.

LIU, K.; BASS, B. Performance of Green Roof Systems. In: COOL ROOFINGSYMPOSIUM, Atlanta, 2005. Proceedings... Atlanta, 2005.

LORENZI, H.; SOUZA, H. M. Plantas

Ornamentais no Brasil. Nova Odessa: Instituto Plantarum, 2008.

MINKE, G. Techos Verdes: planificación, ejecución, consejos prácticos. Colômbia, 2010.

NOWAK, D. J. Institutionalizingurban Forestry as a Biotechnology to Improve Environmental Quality. Urban Forestry \& Urban Greening, v. 5, n. 2, p. 93-100, ago. 2006.

OTTELÉ, M. et al.Comparative Life Cycle Analysis For Green Façades and Living Wall Systems. Energy and Buildings, v. 43, n. 12, p. 3419-3429, dez. 2011.

PERINI, K.; MAGLIOCCO, A. The Integration of Vegetation in Architecture, Vertical and Horizontal Greened Surfaces. International Journal of Biology, v. 4, n. 2, p. 79-91, abr. 2012.

YEANG, K. The Green Skyscraper: the basis for designing sustainable intensive buildings. Prestel, 2000 . 


\section{Carla Matheus}

Departamento de Arquitetura, Tecnologia e Cidade | Universidade Estadual de Campinas | Rua Saturnino de Brito, 224, Cidade Universitária Zeferino Vaz, Barão Geraldo | Campinas - SP - Brasil | Caixa Postal 6143 | CEP 13083-889 | Tel.: (11) 4418-2516

E-mail: matheuscarla@hotmail.com

\section{Fernando Durso Neves Caetano}

Departamento de Arquitetura, Tecnologia e Cidade |Universidade Estadual de Campinas |Tel.: (19) 98278-5858 |

E-mail: durso.arq@gmail.com

Denise Damas de Oliveira Morelli

Departamento de Arquitetura Tecnologia e Cidade | Universidade Estadual de Campinas | Tel.: (19) 3342-5553 |

E-mail: denise_d@uol.com.br

\section{Lucila Chebel Labaki}

Departamento de Arquitetura Tecnologia e Cidade | Universidade Estadual de Campinas | Tel.: (19) 3521-2384 |

E-mail: llabaki@gmail.com

\section{Revista Ambiente Construído}

Associação Nacional de Tecnologia do Ambiente Construído

Av. Osvaldo Aranha, $99-3^{\circ}$ andar, Centro

Porto Alegre - RS - Brasil

CEP $90035-190$

Telefone: +55 (51) 3308-4084

Fax: +55 (51) 3308-4054

www.seer.ufrgs.br/ambienteconstruido

E-mail: ambienteconstruido@ufrgs.br 